\title{
Innovating business processes in public administrations: towards a systemic approach
}

\section{Purpose}

The purpose of this paper is to study the credit collection process in public administrations in order to develop a conceptual model that goes beyond the traditional logic of linearity, adopting system thinking approaches.

\section{Design/methodology/approach}

This study analyses the case of an Italian local government-owned enterprise. Data collection through semi-structured interviews and document analysis has enabled the development of propositions and the identification of systemic variables and the development of an explanatory modeling process based on the system dynamics approach.

\section{Findings}

This paper shows that public administrations can effectively involve external actors, especially citizens, as knowledge and public value co-creators only when considering systemic, unintended, and delayed implications of decision-making activities related to the provision of delicate public services such as credit collection.

\section{Originality/value}

Business process modeling should address some key fragilities of traditional modeling processes, especially in the public sector. This paper develops a novel systemic conceptual model that lays the groundwork for empirically testing business process innovation in public administrations.

Keywords: business process modeling, public administration, system dynamics, new public governance

\section{Introduction}

Most of the management literature on business processes has focused on private companies (Del Giudice, 2016; Scuotto et al., 2016; Trkman et al., 2015), while only limited attention has been paid to public services. Indeed, process innovation is challenging to be addressed in the public sector, which has usually been characterized by incremental changes, limited market exposure, and low propensity to reduce costs and improve their efficiency (Bugge and Bloch, 2016; Rinaldi et al., 2015). The recent paradigm shifts which have characterized the public sector have led public administrations 
and public companies to a greater openness to collaborations that may innovate their business processes (Bryson et al., 2014; Caputo et al., 2019). In fact, after a strict hierarchical control exerted by political bodies over public managers, typical of the Traditional Public Approach (TPA), their decisional autonomy increased with the diffusion of the New Public Management (NPM) and New Public Governance (NPG) approaches (Broucker et al., 2018; Denhardt and Denhardt, 2015; Osborne, 2010). More precisely, according to the NPM approach, public managers should seek a private logic based on efficiency and market orientation. Differently, the NPG model aims to involve external actors, especially citizens, as knowledge and public value co-creators (Bryson et al., 2014). This latter approach has recently attracted the attention of both scholars and practitioners since public administration are increasingly called to manage social complexity and to open up the doors to business processes that consider the social implications of their activities (De Bernardi et al., 2019a). This purpose can be reached by going beyond the logic of linearity, which usually characterizes business processes in public administrations, and adopting system thinking approaches (Porter, 2018).

However, despite the significance of such challenges, very little is known on how business processes in public administrations should be innovated for engaging external actors and citizens as problem-solvers and co-creators of the public value and achieving market efficiency at the same time. This paper contributes to tackle these issues by exploring, through a case study, the credit collection process of an Italian local government-owned enterprise (LGOE). Credit collection is a critical activity for public organizations as it reflects this hybrid logic well. The credit collection process, in fact, gives public administrations the substantial power to force citizens to comply with decisions. However, a strong orientation to market efficiency, without considering the systemic impact of this activity, could lead the public administration to experiment with a permanent decline in the public mind (Hughes, 2010), with a consequent negative impact on its performance. Therefore, the aim of this paper is to rethink the business processes of public administrations for capturing the systemic implications of their activities and help policymakers considering both the intended and unintended effects of their decisions. To do so, the system dynamics (SD) approach has been leveraged for developing a conceptual model of the tax collection activity performed by the LGOE. Indeed, SD is a method particularly adapt to capture those interconnections that are present in dynamic contexts and that traditional modeling methods would not seize due to delays, nonlinearities, and multiple feedback loops (Forrester, 1961; Sterman, 1994).

Giving graphical evidence of the causal loops that characterize complex and dynamic systems, SD can significantly improve adaptive changes in the decision and policy-making processes of organizations and their performance management (Bianchi, 2016; Borgonovi et al., 2018). However, real-world applications of the SD models proposed by the literature are still scant, also because 
policymakers and practitioners often find them too difficult to be understood or that they oversimplify representations of reality (Qudrat-Ullah, 2012; Sorci, 2019). To overcome these issues, scholars have increasingly started to develop SD models using qualitative approaches and involving practitioners through participatory modeling techniques (Wheat and Bardach, 2018). Indeed, qualitative approaches empower the researcher to have a complete understanding of the explored phenomenon, whereas participatory modeling techniques can increase the understanding of the involved manager or decision-maker of the constructed model as well as his satisfaction with it (Papachristos and Adamides, 2016; Wheat and Bardach, 2018; Wolstenholme, 2004). Therefore, the results of this study show that linear process models are not sufficient for the effective integration of the NPG approach and for capturing systemic, unintended, and delayed implications of decision-making activities related to the provision of public services. Conversely, public organizations should adopt a systemic approach and key performance indicators different from traditional, financial ones in order to manage the increasing complexity of public administrations, especially in the case of delicate processes such as credit collection (De Bernardi et al., 2019b). Drawing on the SD approach, a conceptual model has been developed, laying the groundwork for empirically testing business process innovation.

This paper principally contributes to three bodies of literature. First of all, it adds to the literature on business process management (Al-Mashari, 2003; Dumas et al., 2013; Fosso Wamba, 2017) by developing a conceptual model for rethinking processes in public administrations. Second, it offers remarkable insights into the literature on public administrations by focusing on finding a way to integrate the NPG model in public administrations (Bryson et al., 2014; Osborne, 2010). The literature on SD approach (Bianchi, 2016; Borgonovi et al., 2018; Tan et al. 2018) can benefit as well from this paper since its methodology is applied to the tax collection process of a public administration, opening the doors for further applications to other similar processes. The practical implications of this study will be discussed in depth in the conclusion section.

The remainder of this paper is structured as follows. Section 2 discusses the methodology of the work. Section 3 develops the propositions based on the analysis of the current literature and the empirical data. Section 4 discusses the AS-IS and the TO-BE scenarios related to the credit collection process of the case under analysis, by comparing the current linear process with the SD model. The paper concludes with Section 5, which provides implications, limitations, and related possible avenues for further studies.

\section{Research context and design}

The research followed a qualitative and explorative approach, adopting the case study methodology (Stake, 1995; Yin, 2017), which plays an important role among qualitative methods, as it aims to 
generate insights from field-based data (Parker, 2012). Eisenhardt and Grabner (2007) argued that data arising from case studies, and current literature are essential to build explicit propositions and theories.

Qualitative methods are particularly appropriate to highlight the management decision making processes and the relative effects of particular management approaches (Yin, 2017). Moreover, the lack of studies that investigate business process modeling in public administrations highlights the need to develop qualitative case studies to gain intimate knowledge on this topic. The case study is focused on an LGOE located in a highly-populated area of Northern Italy. The most common approach adopted by the public sector in Italy is the NPM (Dent, 2005; Wollmann and Marcou, 2010), even whether theoretical distinctions are not always clear in the operational business processes. The organization object of analysis, which will be called CREDIT SpA to ensure anonymity, was born as a company specifically set up by the Municipality for collecting unpaid local taxes (e.g., related to waste, properties, public areas' occupation) and fines (e.g., related to traffic violations, late payments). In this regard, it was chosen not to entrust the service to the National Agency in order to guarantee greater attention towards specific situations that otherwise would had be ignored. However, although any law imposed it, CREDIT SpA's managers voluntarily enrolled the company to the national list of credit collectors (Register of Dealers) for ensuring the respect of the same technical, financial, and ethical requirements requested to the National Agency by law. Indeed, this kind of activity is typically considered critical within public services, as it impacts not only the financial stability of a public organization itself but also the role it plays in the institutional environment and citizens' lives. The choice of CREDIT SpA as the unit of analysis is justified by three aspects, which make this case unique (Stake, 1995) and allow to gain specific insights that other organizations would not provide (Siggelkow, 2007). First, this organization has a unique situation since a Municipality represents its client and its shareholder at the same time. Indeed, this public institution owns $90 \%$ of CREDIT SpA shares (with the remaining 10\% owned by another public institution) whilst the company has to collect credits for the Municipality. Second, recognizing the company's contribution to the creation of public value, its managers would implement the NPG approach and KPIs related to the creation of public value in the business processes, considering more the needs of CREDIT SpA's users (i.e., the citizens). Third, the managers have recently embarked on a path oriented towards the involvement of external actors (i.e., NGOs and citizens associations) to innovate their business process and overcome constraints that could depend on a more traditional view of the owning public institutions.

The research unfolded through a number of steps. First, the AS-IS scenario was defined to understand what is the actual workflow of CREDIT SpA's business processes. Second, based on the literature 
review, and information that emerged from interviews and document analysis, four propositions were developed. Third, based on these propositions, the key variables and their related feedbacks were identified, and an SD model conceptualized (Nikolaou et al., 2015). Especially, a causal loop diagram is presented as the TO-BE scenario. Figure 1 presents the research design.

\section{PLEASE INSERT FIGURE 1 HERE}

In qualitative research, the researcher carries out a series of different activities, such as interviews, observation, interpretation of documents, and intense self-reflection (Janesick, 1994). All these activities allow to understand, reconstruct, and interpret the phenomenon of interest and, specifically, it is necessary to employ a variety of perspectives and interpretations to guarantee triangulation (Rhineberger et al., 2005).

In this case, data were collected through interviews and document analysis (Gibbs, 2007). The data collection started in January 2018 and ended in March 2019. The semi-structured interviews lasted between 45 and 60 minutes and involved managers from both the Municipality of Turin and the LGOE. All the key informants were selected following a purposive sampling technique and according to their knowledge and availability (Kumar et al., 1993; Patton, 2002). Data saturation was reached after 12 interviews (Table 1). Having interviewed various key-informants at different levels of the enterprise's hierarchy, diverse points of view could be obtained and information that came out from different sources coded and compared (Patton, 2002). The interviews took place, where possible, in the interviewee's office at foundation premises in order to increase the confidence and trust (Leardini et al., 2019), except for two interviews, which were carried out via Skype.

The semi-structured interviews were conducted by one researcher, while a second one was in charge of taking field notes and scrutinizing the behavior and the approach of the interviewee in answering questions (De Bernardi et al., 2019a). The use of in-depth interviews allowed the researchers to analyze the topic under question according to the perspectives, experiences, and opinions of the interviewees (Silverman, 2013). Moreover, the adoption of semi-structured interviews based on openended questions enabled to discuss any new queries that emerged during the meetings (Gilham, 2005). Interviewees were first contacted by a phone call to present the research project in brief. The call was followed by an email that contained a more specific focus on the aim of the interview, without revealing specific questions in order to avoid that the answers were prepared in advance (Easton, 2010). All the interviews were recorded and transcribed independently by two authors. Subsequently, they were integrated through a process of data triangulation (Eisendhardt, 1989) based on document analysis from website text, statutes, organization reports, press releases, and any other documents 
available on the foundations' websites (Patton, 2002; Wolff, 2004). These documents enriched the hermeneutic unit of analysis and helped to gain further understanding of manager behaviors and other particular details (Locke, 2011). The coding procedures of the collected documentation were carried out by three authors and then compared to reduce biases and to strengthen reproducibility, precision, and rigor of this research (Strauss and Corben, 1990). In the first coding phase, the authors discovered, named, and categorized codes and memos regarding the investigated phenomenon independently. Then, when the three authors involved in the open coding phase came up with a shared interpretation of the results, data were reorganized and synthesized using an axial coding procedure (Bryman and Bell, 2011). So, connections among the elaborated categories and between categories and possible sub-categories could be constructed. At the second coding phase, the hermeneutic unit was analyzed through a merged codes list built also considering common labels inspired by literature (Ferraris et al., 2018; Roulston, 2010).

\section{PLEASE INSERT TABLE 1 HERE}

\section{Propositions development}

Three different managerial approaches have characterized public organizations over the years: Traditional Public Administration (TPA) approach, New Public Management (NPM) approach, and New Public Governance (NPG) approach (NPG). Although each of these approaches is aimed at improving the level of the services provided and citizens' wellbeing, the organization's objectives and the business processes behind them significantly differ. According to the TPA, which was the most diffused approach until the 1970s, organizations are organized following clearly defined hierarchies (Osborne, 2010). Consequently, public service recipients are viewed primarily as voters, and public managers must focus on the efficiency of the procedures to implement politically defined goals (Denhardt and Denhardt, 2003). The mechanisms to achieve these goals rely on a robust bureaucratic logic that has its roots in hierarchical structures and the centralization and standardization of procedures (Bryson et al., 2014).

At the beginning of the 1980 s, with the idea of improving public organization efficiency and effectiveness, the NPM became the prevalent approach in guiding public organizations. This model, born and spread originally in the Anglo-American countries like the UK, New Zealand, and Australia, is nowadays widespread (Klijn, 2012). The NPM introduces some of the logics typical of the private sector in managing public organizations, such as: (1) the introduction of results instead of rules as a guiding principle; (2) the sensitization of managers on individual responsibilities; (3) the introduction of the accrual principle rather than cash-based accounting or public subsidies; (4) the improvement 
of the accessibility to services and their quality. As a consequence, some scholars have blamed the NPM for having reduced the public influence in favor of a private, market-driven logic aimed at improving public companies' performances. Thanks to this approach, public service recipients started to be viewed as customers or clients and public managers as subjects that should be free from political and bureaucratic constraints (Denhardt and Denhardt, 2015). In this regard, the NPM laid the basis for the constitution of specific companies for providing public services, such as the tax collection service, either autonomous or semi-autonomous from public bodies.

The two paradigms of TPA and NPM, however, have found to be uncomfortable with the recent changes in the socio-economic environment due to increasing globalization, technological development, and greater openness of political systems (Bryson et al., 2014; De Bernardi et al., $2019 \mathrm{~b}$ ). Based on these assumptions, the recent literature on public organizations has introduced a new model (i.e., the NPG) in opposition to the linear structure based on a hierarchical bureaucracy that characterizes the TPA and the dualist government-market structure that is typical of the NPM (Thompson and Rizova, 2015; Xu et al., 2015). The NPG views public service recipients essentially as co-creators of the common good and public companies as organizations placed at the citizens' service rather than enactments of the public authority. As a consequence, this approach claims that public managers should catalyze and enable a dialogue-driven engagement with all the actors into democratic and networked activity systems, overcoming the traditional boundaries that exist among the government, the hierarchy, the market, and the citizens (Bryson et al., 2014; Stoker, 2006).

Together with other elements such as law regulations and the progressive alignment between information technologies and organizational processes, this increasing attention towards stakeholders' interests represents an enabling factor for business process innovation in public organizations (Bititci et al., 2005; Bresciani et al., 2017; Dumas et al., 2013).

Actually, however, many of the processes characterizing public administrations (e.g., credit collection) are still anchored to old logics. Indeed, on the one hand, public administrations recognize how important it is to involve stakeholders in networked and collaborative governance as a guarantor of public value, while, on the other hand, they lack a systemic vision to integrate the NPG perspective in their business processes.

The NPG model determines the common good by leveraging a broadly inclusive dialogue and deliberation based on democratic and constitutional values (Denhardt and Denhardt, 2015). A greater centrality of citizens should, therefore, be reflected in greater orientation towards their needs (Bryson et al., 2014). The controller of the LGOE (C3) recognized that the strict control exerted by the Municipality is detrimental to the autonomy of the LGOE's managers and this aspect reduces the quality of the tax collection activity. In fact, the LGOE is required to follow specific protocols that 
often inhibit the building of trust-based relationships with citizens. The key proposition arising from the analysis above is:

P1. A strict hierarchical control exerted by the public body reduces the autonomy of company's managers and the quality of the tax collection process, decreasing the orientation towards citizens' needs.

Within a networked governance model, the attention should not only be limited to citizens despite the fact that the credit collection is addressed directly to them (De Bernardi et al., 2019a).

Indeed, public administrations operate in an environment that involves numerous institutions (Aalto and Kallio, 2019). Business processes should also take into account other stakeholders (Osborne, 2010). A greater orientation to the public value, typical of the NPG model (Bryson et al., 2014), would allow public administrations to improve their image and to gain legitimacy, which is fundamental in the field of credit collection (De Bernardi et al., 2019a). The director of the Municipality participation area (M1) has highlighted that "The decision to entrust the debt collection process to a local company is due to the fact that a local presence, as it is more deeply rooted in the territory, could have a positive impact on citizens. In Italy, in fact, the credit collection system is traditionally entrusted to a national body (i.e., "Agenzia delle Entrate"), which is often viewed with distrust by citizens". The interviews have also shown that the improvement of the company image has favored the establishment of relationships with NGOs. Hence, the second proposition of this work is:

P2. Improving the company image will result in more external collaborations.

Bureaucracy is seen by the TPA approach as leverage of efficiency (Bryson et al., 2014). However, an excessive orientation towards a bureaucratic logic might lead citizens to feel overwhelmed (De Bernardi et al., 2019a). The interviews revealed that the citizens have often relied on usurers in order to respect the deadlines imposed by the LGOE. Moreover, this practice is often typical of the most conscientious and sensitive citizens towards the public good.

In order to preserve their image in the short term, citizens worsen their insolvency in the long run. This aspect should not be overlooked by public administrations. Based on these previous findings, the authors propose that: 
P3. A hierarchical and centralized rules-based model may cause social fragility by leading customers to rely on usurers as a liquidity source.

The market-driven logic rooted in the NPM model assumed the technical and economic rationality as a model of human behavior. Humans are seen as "economic men", and decision-makers are mainly driven by self-interest (Bryson et al., 2014). According to this model, managers gain flexibility and are not limited to agency restrictions. However, one of the main criticisms is the risk that public managers move away from trying to meet citizens' needs (Denhardt and Denhardt, 2015). The strong goal orientation, typical of this model, may lead the process of credit collection to incur in coercive practices. Although these practices can facilitate the tax collection on the one side, they can be detrimental to the willingness of citizens to pay.

P4. A market-driven logic resulting in coercive practices reduces citizens' willingness to collaborate in the long-term.

\section{Development of the model}

\subsection{AS-IS scenario}

In this section, the actual workflow followed by the Municipality and the LGOE in collecting citizens' taxes is presented. The AS-IS mapping was constructed through the interviews and document analysis conducted to both Municipality and CREDIT SpA's managers and employees. For what regards the Municipality, after the public service is provided, a credit towards citizens arises. If citizens do not pay the amount due on their own, the credit is entrusted to CREDIT SpA, whose activity can be distinguished in two fundamental aspects. The first concerns the traditional activities related to tax assessment, collection, and liquidation, whose workflow is shown in Figure 2.

\section{PLEASE INSERT FIGURE 2 HERE}

After the company receives the credit from the Municipality, it proceeds with the evaluation of the fiscal position of the citizen and starts performing the collection activity. The citizen can pay its debts on his own, at banks, postal offices, or other shops, as well as through apps or online services, or at the company's headquarter, where staffed and automatic cash desks are present. Conversely, if the citizen is not solicited to pay after receiving the first letter, the company can activate different procedures to collect the unpaid tax. The entire process is shown in Figure 3. 


\section{PLEASE INSERT FIGURE 3 HERE}

However, tax collection is a delicate activity that touches different sensitivities and could lead to unintended consequences when people that would pay but do not have the right means are involved. In this sense, the second aspect comes to the fore. In 2005 the Municipality decided to entrust the tax collection service to a specific local company and not to the Italian national agency since its ability to have a presence and an awareness of the territory in which it operates. The reasons behind this choice were highlighted by the Executive of the Municipality participation area (M2): “a company with such peculiarities could have totally different attention toward citizens and the possibility to build direct relations with them, which is a significant aspect of what regards the collection of local taxes". Following this idea, since its establishment, the company voluntarily decided to set up a consultancy and support service in its offices in order to help citizens, especially the most fragile ones, to understand their fiscal position and how to relieve it. Over the years, as stated by the CRO of CREDIT SpA (C2), the company has followed an incremental innovation process, re-defining its spaces and part of its processes. "We separated the waiting room from the front-office desks for lowering the stress the users would feel being perfectly aware of how much time other people would take to address their issues. We also involved some psychologists in delivering training and development programs to the company's staff, enabling them to improve their communication and conflict-management skills". Citizens were also involved in improving the deeds the company sends to taxpayers, so to make those documents easier to be understood, and a feedback station was built to collect users' feedback on how to improve the services offered (on-site sentiment analysis). As a result, a relax area and a changing table for infants have been provided, or automatic cash desks and IT-based booking systems have been implemented.

In Figure 4 is shown the ideal flow that a user would follow in the AS-IS scenario. A security officer welcomes the citizen with a twofold objective. First, he is obviously in charge of keeping the place safe. On the other hand, he plays a fundamental role in listening to users' needs, providing them general and preliminary information, and helping them to find how their problem can be best addressed. If they cannot solve their problem on their own, the users are invited to enter the waiting room after having taken a ticket. Finally, crossing a corridor that connects the waiting room with the front-office desks, the access to the consultancy and cash services is granted. Also this decision to force people walking from a room to another to reach these services has been suggested by psychologists as a stress reliever. In the end, the user is invited to provide his feedback about the service received before exiting the company's offices. 
Interestingly, a strong cohesion has been built among the 24 front-office clerks. A front desk employee of CREDIT SpA (C5) recognized that "Despite the stressful situation in which we have to operate, we have developed a strong cohesion over the years, sharing convivial moments also out of their work time and adapting flexible work procedures for offering the best service possible to the citizen. In my opinion, these practices also contribute to build a good company image over the years".

\section{PLEASE INSERT FIGURE 4 HERE}

\subsection{TO-BE scenario}

In this research, a SD model is developed to capture the complexity characterizing the TO-BE scenario desired by the company and the co-presence of different, usually conflicting, logics (Figure 5). SD can represent a powerful tool for visualizing and organizing business processes, identifying their patterns and causal connections. Moreover, it can help in the formulation of business process models that define problems dynamically, think of all concepts in the real system as interconnected in loops, identify the key variables essential to address the problem, and formulate a richly explanatory behavioral model capable of reproducing the dynamic problem of concern (Maani and Cavana, 2007; Richardson and Andersen, 2010). Especially, a causal loop diagram is conceptualized, highlighting links among variables that can be positive (in blue) or negative (in red), and that form vicious or virtuous closed loops (Forrester, 1976; Sterman, 2000). If an even number of negative links (or none) connects each variable, the loop would be self-reinforcing (labeled with an "R"). If an odd number of negative links connects each variable, the loop would be self-balancing (labeled with a "B"). Conversely, the term closed should be intended as loops that are causally closed and not be confused with its usage in systems theory, where it is referred to systems that do not share information with external systems (Richardson, 2011, p. 241). The causal loop diagram presents a number of key variables that are related to CREDIT SpA's operativity, financial performances, hierarchical structure, and external collaborations. Moreover, the level of public services and the consequent citizens' trust toward the public administration, the efficiency of the legal system, and some constraints posed by the Municipality for what regards the hiring policy are considered as external variables that affect CREDIT SpA's activity but are not under its direct control. In the next sections, the different loops that compose the causal loop diagram and their relationship with the four propositions will be discussed in detail. 


\subsubsection{Political interferences and company's autonomy}

The first loop that is presented is B1 - political interferences, which is related to the first proposition:

P1. A strict hierarchical control exerted by the public body reduces company's managers autonomy and the quality of the tax collection process, decreasing the orientation towards citizens' needs.

As can be noted in Figure 6, political interferences are a direct consequence of the Municipality's capability to subsidize its participated companies. However, less decision-making autonomy of CREDIT SpA's managers results in a more focus on achieving the KPIs requested by the Municipality, which are mainly based on financial aspects. Not delivering the right value to all the company's stakeholders, primarily citizens, would result in lower quality of the offered services and potential reputational issues. With a delay, this would also affect the company's revenues and the dividends it can pay to the Municipality. In the end, the loop is self-balancing since the Municipality would lose power over the company, but with unintended consequences within the system.

Political interferences also result from the presence of hiring constraints, which are a variable external from those drivers that can be leveraged by the company. Indeed, actually CREDIT SpA can hire new managers and employees only among other LGOES' redundancies. Subsequently, this restriction is reflected in less motivation among actual employees, due to a higher workload, and the impossibility to acquire specifically skilled and trained staff. In C1's words: "since the Region has become our customer, our operative workload has tripled, but we have several constraints on hiring new employees because we have to hire staff, both employees and managers, only from the Municipality ecosystem. These constraints have repercussions on the quality of the services we provide to our customers since the employees are not sufficiently trained, while managers remain in charge of too many strategic activities resulting in workload". However, skilled and trained staff are fundamental requisites for offering a high-quality service to citizens and keeping the company's reputation level high. Thus, also CREDIT SpA's revenues, directly linked to the dividends it can pay to its shareholders, are affected by the hiring constraints set by the Municipality. In the end, also this situation would lead to less budget for the Municipality and scarcer possibilities to exert political power over its participated companies. 
These circumstances can be empirically observed in CREDIT SpA. Although the company has always registered profits since its creation, most of them have always been distributed as dividends, limiting the company's self-financing possibilities. Interestingly, there was an increase of about four times in the amount of distributed dividends from 2007 to 2018 , when around the $95 \%$ of the company's net profit (approximately $1 \mathrm{mln}$ Euros) was paid out to the company's shareholders, with a solid return on equity (ROE) of $24,36 \%$. Moreover, although CREDIT SpA's operations have noticeably increased after the Region became a company's shareholder in 2017, its managers claim to be understaffed.

Conversely, for what regards the company's accountability, namely the KPIs the Municipality asks the company to achieve, they are mainly focused on the operational (e.g., capital recovered out of total capital entrusted, number of cases handled out of total cases assigned) and economic aspects (e.g., ROE, return on investment, interest coverage ratio). However, in this way, the broader and systemic impact the company may have on improving the quality of life of citizens is missed. KPIs that would capture them could be, for example, related to reputation risks, contrast to social fragility, adoption of innovative techniques (C2: "We would like to be able to consider also KPIs measuring the degree of customer satisfaction when going out of our offices. In fact, it is part of our policy to serve all our customers best").

\subsubsection{External collaborations and social fragilities}

In this section, two loops that describe the company's interactions with external actors are presented (Figure 7). The first, B2 - PPPs (public-private partnerships) is a self-balancing loop deriving from the second proposition developed in this study:

P2. Improving the company image will result in more external collaborations.

The quality of the services offered by the company, which is fundamental for improving the company image and building users' trust, can also lead to more collaborations with NGOs. In CREDIT SpA's situation, this means guiding and helping citizens to access to soft loans. Subsequently, having more liquidity at facilitated conditions, and the possibility of accessing to it leads to a higher willingness of citizens to relieve their unpaid taxes and, consequently, the company and Municipality revenues from tax collection. The loop is self-balancing due to the effect of political interferences that can be exerted on the company when the Municipal capacity to subside LGOEs increases. This situation would result in less autonomy of CREDIT SpA and a lower level of its offered services, with scarcer possibilities to collaborate again with NGOs, mainly composed of voluntary citizens. Although it could result in more costs in the short-term, wise decision-makers 
would exert a milder control on the participated company for allowing it to increase the quality of its services and increasing citizens' willingness to contribute to common goods in the long-term. In this sense, both the NPM logic of increasing processes efficiency and efficacy and the NPG logic of considering the systemic implications of the business activity would be followed for increasing overall performances.

\section{PLEASE INSERT FIGURE 7 HERE}

The second loop examined in this section is the reinforcing loop R1 - social fragility, which is linked to the third proposition:

P3. A hierarchical and centralized rules-based model might cause social fragility by leading customers to rely on usurers as a liquidity source.

Observing Figure 7, it is clear that a higher quality of the services offered by CREDIT SpA can also lead to a reduction of the number of citizens that would pay their taxes but have no enough money to do that, so they accede to illegal channels for raising their liquidity. In CREDIT SpA's situation, this means subtracting people from usury, when there is a lack of alternative accessible financial solutions. R1 is a self-reinforcing loop since more liquidity would lead to higher taxes collected from citizens; this would result again in less autonomy of CREDIT SpA's managers and a decrease in the quality of its services. As a consequence, more citizens would recur to alternatives, including illegal ones, resulting in a reinforcement of social fragility. Wise decision-makers would improve the company possibilities to limit this loop through its operativity.

Citizens' willingness to pay taxes is affected also by the level and quality of services the public institution is able to deliver and the consequent trust that citizens have toward the Municipality in using the money collected from taxes. These variables not only are external to the considered model, but it takes time to build citizens' trust toward the Public Administration and convincing them to leverage the Municipality's budget through taxes and keep high quality level of the delivered services. In this sense, engaging citizens as co-developer of public value, with their direct involvement in decision-making processes or better communicating Municipal efforts for improving its outcomes, can lead to steady results and a reduction in the display of this delayed effect.

\subsubsection{The coercive collection activity}


Another self-reinforcing loop is generated from the coercive collection activity performed by the company (Figure 8). This loop, R2 - coercive collection activity is linked to the fourth proposition of this research:

P4. A market-driven logic resulting in coercive practices reduces citizens' willingness to collaborate in the long-term.

Interestingly, a higher quality of the services offered by CREDIT SpA limits the necessity to perform the coercive collection activity, which is manifested in injunctions sent at contributors' homes. The injunctions lead to an increase in the citizens' perception about the punishment certainty, directly or after a fiscal inspection. R2 is self-reinforcing. Indeed, make citizens pay increases the Municipality's budget but its political power as well. So, a decrease in the company's quality level would increase the necessity to recur to the coercive action, conveying fewer citizens to alternative solutions for relieving their fiscal positions. In this regard, leveraging the company on KPIs that strictly consider financial aspects would result detrimental in the long-term for both social implications and economic returns of CREDIT SpA's activity.

In this regard, the efficiency of the legal system is considered as an external variable which is able to positively impact on the amount of collected taxes. In fact, more time is necessary settle pendent trials, the less taxes will be collected. Similarly, trials often lead to not relieve the fiscal position of the taxpayer, neither collecting taxes due to the ability of some citizens to elude the payment through sophisticated legal tricks (e.g., declaring personal bankruptcy).

\section{PLEASE INSERT FIGURE 8 HERE}

\section{Discussion and conclusion}

The collection of local taxes is a delicate task to deal with since it can have a tremendous impact on people's life. However, public institutions often show a myopic vision, focusing their attention on traditional financial KPIs in line with the consolidated TPA and NPM approaches. In several of the activities performed by CREDIT SpA, the co-presence of different managerial approaches can be observed. Provided that the willingness to operate for creating shared value between citizens and public institutions is intimately rooted in the company's vision, also the Municipality showed great attention toward local peculiarities when it decided to set up a specific company for collecting local taxes. Conversely, this attention is somewhat in contrast with more traditional logics aimed at leveraging a strong hierarchy or efficiency KPIs. For example, the co-existence of a more traditional approach leading to political interferences exerted on the company (Garrone et al., 2013), and the 
NPM approach, which stresses more on the improving the company's financial performances, should be mitigated by the logics that characterize the NPG approach. So, the three approaches should be complementary to each other (Esmark, 2017; Svara, 2001) and taking care of citizens' needs would result in better results for all the stakeholders involved by CREDIT SpA's activity (Hughes, 2010; Bryson ). The same results are confirmed for what regards contrasting social fragility and opening to external collaborations that could provide citizens solutions to relieve their fiscal position (Bryson et al., 2014; Caputo et al., 2019).

However, a systemic model that is able to capture the interdependencies of the different activities is still lacking. This is also due to a substantial presence of linear business process models, which foster public institutions to consider the direct consequences of their action rather than their systemlevel implications. So, effective integration of the NPG approach, together with the development of SD models in public administrations, should avoid institutional myopia and increase the participation of external actors in determining the decision-making processes. In response to a changing socioeconomic environment, the demand for taking these issues into considerations is grown to the extent that some studies have started talking about "Dynamic Performance Governance" (Bianchi et al., 2019). The causal loop diagram proposed in this study highlights the need to coordinate the Municipality and LGOE activities for achieving these results and showed a real-world case of a company that is trying to integrate these assumptions into its business activity. In this regard, it should be noted that a Municipal Resolution has recently been implemented to give more control to the Public Body on its participated companies. This has been made with the aim to integrate their different business processes and it could also represent an opportunity of supporting CREDIT SpA's willingness of innovating its processes to capture their systemic impact. As a consequence of this Resolution, that introduced the so-called analogous control, more on-site audits and meetings have taken place between LGOEs' managers and the heads of the holding area of the Municipality. So, this changes represent the breeding ground to ensure the implementation of the model presented in this study.

This paper provides theoretical contributions to at least three bodies of literature. First of all, the study contributes to the literature on BPM (Al-Mashari and Al-Mudimigh, 2003; Del Giudice and Della Peruta, 2016; Laurenza et al., 2018; Senneset et al., 2010; Trivelli et al., 2019) in particular to business process modeling (Weske, 2019), by promoting a shift from linear to systemic business process models in public administrations in order to effectively innovate their business processes (Bianchi, 2010; Lane et al., 2010; Leat and Setzler, 2002; Padua and Jabbour, 2015). The conceptual framework developed in this study allows public administrations to exercise their power by actively 
involving outside players and to increase their awareness about the social impact of their activities (Ashok et al., 2016; Hughes, 2010; Rundh, 2009).

This paper also contributes to the literature on public administration by providing empirical evidence on how public organizations can effectively introduce the NPG approach and integrate it with the NPM (Osborne, 2010), by focusing on a critical process such as credit collection (De Bernardi et al., 2019a; Joseph, 2012; Hinna et al., 2018;). Despite certain ideological polarizations arguing that the NPG should completely replace older rhetorics, NPG and NPM can be viewed in practice as complementary to each other (Esmark, 2017). However, due to the excessive theoretical orientation of the previous studies, few papers had so far tried to explain how the integration between these two approaches can effectively take place.

The third literature stream which benefits from this study is related to the SD approach (Richardson, 2011). The creation of public value, as one of the fundamental goals of today organizations, requires a holistic approach, with more significant considerations of real-world problems and relationships among variables in real complex systems (Bianchi, 2010; Lane et al. 2010; Leat and Setzeler, 2002). In this regard, SD represents a proper approach to overcome these challenges and support policy design. Indeed, whilst the first studies were limited to industrial applications, nowadays this approach is recognized as useful to capture the social and economic implications of businesses' activity (Sterman, 2000) and public organizations over time (Bianchi, 2010; Bianchi, 2016; Borgonovi et al., 2018). However, to the best of the authors' knowledge, despite the applicability of the SD model to complex social, managerial, economic, and ecological systems, no previous studies have tried to analyze credit collection processes of public administrations under the SD lens.

The findings obtained in this research reveal remarkable insights both for managers and policymakers. First of all, this research proposes a systemic model, which helps public managers to find the right mix of decisional levers that can be anchored not only to operational and financial but also to social logics. Thanks to this study, the managers in charge of the debt collection practices can realize that the views of citizens are quite valid inputs, and opinions from outside should be seen as essential elements for stimulating a networked vision without jeopardizing the administration power (Hughes, 2010). Moreover, increasing manager awareness towards systemic aspects may open the doors to more effective communication of their own services to the citizens, improving the corporate social responsibility (Bivona and Daza, 2009). In a similar vein, the study allows policymakers to evaluate the systemic effect of their actions. In fact, this approach allows to overcome the hierarchical vision oriented to the optimization of cash flows and provides the tools to perform simulations on the possible direct, indirect, and delayed effects of new policies, otherwise hidden (Akkermans and Van 
Oorschot, 2018; Ghaffarzadegan et al., 2011). According to the findings of the study, in fact, an efficiency-driven logic can be detrimental in the long-term by decreasing customers' willingness to collaborate and to pay, as in the case of credit collection process.

However, this paper is not free from limitations, which pave the way for further studies. The model was developed adopting qualitative techniques, based on the information identified from the literature and from the data collection phase. Future developments should be based on identifying variables that are linked to the causal loop diagram and build a stocks and flow diagram. Indeed, stocks and flow diagrams enable to give graphical evidence of the relationships that elapse among: (1) the variables whose amount is given (stocks); (2) the drivers from which their accumulation or depletion paths depend on (flows); and (3) the output and outcome of the process, where the former are the end-results of the analyzed process and the latter will become new inputs. So, this kind of diagram would help identifying the key variables that are essential to formulate a richly explanatory behavioral model capable of reproducing the dynamic problem of concern. Moreover, further research should enrich and validate this conceptual model by introducing a dashboard of indicators for measuring both economic and social performance and by finding out the value of the model in a wide range of practical applications, simulating its application with different types of stakeholders' engagements, and different policies. 


\section{REFERENCE LIST}

Aalto, K., and Kallio, K. M. (2019), "Changing institutional logics: shifting to a new service model in the Finnish public sector", Public Money \& Management, Vol. 39 No. 7, pp. 486-493.

Akkermans, H. A., and Van Oorschot, K. E. (2018), "Relevance assumed: a case study of balanced scorecard development using system dynamics", in Kunc, M. (Ed.), System Dynamics, Palgrave Macmillan, London, pp. 107-132.

Al-Mashari, M. (2003), "Enterprise resource planning (ERP) systems: a research agenda”, Industrial Management \& Data Systems, Vol. 103 No. 1, pp. 22-27.

Al-Mashari, M. and Al-Mudimigh, A. (2003), "ERP implementation: lessons from a case study", Information Technology \& People, Vol. 16 No. 1, pp. 21-33.

Ashok, M., Narula, R., and Martinez-Noya, A. (2016), "How do collaboration and investments in knowledge management affect process innovation in services?", Journal of Knowledge Management, Vol. 20 No. 5, pp. 1004-1024.

Bianchi, C. (2010), "Improving performance and fostering accountability in the public sector through system dynamics modeling: from an 'external' to an 'internal' perspective", Systems Research and Behavioral Science, Vol. 27 No. 4, pp. 361-384.

Bianchi, C. (2016), Dynamic performance management (Vol. 1), Springer, Berlin.

Bianchi, C., Bereciartua, P., Vignieri V. and Cohen, A. (2019), "Enhancing Urban Brownfield Regeneration to Pursue Sustainable Community Outcomes through Dynamic Performance Governance", International Journal of Public Administration.

Bititci, U., Cavalieri, S., and Cieminski, G. (2005), "Implementation of performance measurement systems: private and public sectors", Production Planning and Control, Vol 16 No. 2, pp. 99-100.

Bivona, E., and Daza, S. H. (2009), "Implementing a sustainable CSR Strategy through a System Dynamics Perspective: evidences from a Colombian case-study", in The 27th International Conference of the System Dynamics Society, Albuquerque, pp. 1-23.

Borgonovi, E., Anessi-Pessina, E. and Bianchi, C. (2018), Outcome-based performance management in the public sector, Springer, Cham. 
Bresciani, S., Del Giudice, M., and Papa, A. (2017), "Public control and strategic governance in stateowned public utilities: empirical evidence from Italian listed firms", Sinergie Italian Journal of Management, Vol. 102, pp. 47-64.

Broucker, B., De Wit, K. and Verhoeven, J. C. (2018), "Higher education for public value: taking the debate beyond New Public Management”, Higher Education Research and Development, Vol. 37 No. 2, pp. 227-240.

Bryman, B. and Bell, E. (2011), Business Research Methods, Oxford University Press, Oxford.

Bryson, J. M., Crosby, B. C. and Bloomberg, L. (2014), "Public Value Governance: Moving beyond Traditional Public Administration and the New Public Management”, Public Administration Review, Vol. 74, pp. 445-456.

Bugge, M. M., \& Bloch, C. W. (2016), "Between bricolage and breakthroughs - framing the many faces of public sector innovation”, Public Money \& Management, Vol. 36 No. 4, pp. 281-288.

Caputo, F., Garcia-Perez, A., Cillo, V. and Giacosa, E. (2019), "A knowledge-based view of people and technology: directions for a value co-creation-based learning organisation", Journal of Knowledge Management, Vol. 23 No. 7, pp.1314-1334.

De Bernardi, P., Ricciardi, F., Forliano, C. and Sorano, E. (2019a), "How Pioneering Managers Strive to Integrate Social Risk Management in Government Debt Collection”, in De Vincentiis, P., Culasso, F., Cerrato, S.A. (Eds.), The Future of Risk Management, Volume I. Perspectives on Law, Healthcare, and the Environment, Palgrave Macmillan, Cham, pp. 269-302.

De Bernardi, P., Venuti, F., and Bertello, A. (2019b), "The Relevance of Climate Change Related Risks on Corporate Financial and Non-Financial Disclosure in Italian Listed Companies", in De Vincentiis, P., Culasso, F., Cerrato, S.A. (Eds.), The Future of Risk Management, Volume I. Perspectives on Law, Healthcare, and the Environment, Palgrave Macmillan, Cham, pp. 77-107.

Del Giudice, M. (2016), "Discovering the Internet of Things (IoT) within the business process management: a literature review on technological revitalization", Business Process Management Journal, Vol. 22 No 2, pp. 263-270.

Del Giudice, M. and Della Peruta, M. R. (2016), “The impact of IT-based knowledge management systems on internal venturing and innovation: a structural equation modeling approach to corporate performance", Journal of Knowledge Management, Vol. 20 No. 3, pp. 484-498. 
Denhardt, J. V. and Denhardt, R. B. (2003), The New Public Service: Serving, Not Steering, Third Edition, M. E. Sharpe, Armonk, NY.

Denhardt, J. V. and Denhardt, R. B. (2015), "The new public service revisited", Public Administration Review, Vol. 75 No. 5, pp. 664-672.

Easton, G. (2010), “Critical realism in case study research”, Industrial marketing management, Vol. 39 No. 1, pp. 118-128.

Eisenhardt, K. M. (1989), "Building theories from case study research", Academy of management review, Vol. 14 No. 4, pp. 532-550.

Esmark, A. (2017), "Maybe it is time to rediscover technocracy? An old framework for a new analysis of administrative reforms in the governance era", Journal of Public Administration Research and Theory, Vol. 27 No.3, pp. 501-516.

Ferraris, A., Santoro, G., Bresciani, S. and Carayannis, E. G. (2018), "HR practices for explorative and exploitative alliances in smart cities: evidences from smart city managers' perspective", Management Decision, Vol. 56, No. 6, pp. 1183-1197.

Forrester, J. W., (1961), Industry dynamics, MIT Press, Cambridge.

Forrester, J.W., (1976), "Business structure, economic cycles, and national policy”, Futures, Vol. 8 No.3, pp. 195-214.

Fosso Wamba, P. S. (2017), "Big data analytics and business process innovation”, Business Process Management Journal, Vol. 23 No. 3, pp. 470-476.

Garrone, P., Grilli, L. and Rousseau X. (2013), "Management Discretion and Political Interference in Municipal Enterprises. Evidence from Italian Utilities”, Local Government Studies, Vol. 39 No. 4, pp. 514-540.

Ghaffarzadegan, N., Lyneis, J. and Richardson, G. P. (2011), "How small system dynamics models can help the public policy process" System Dynamics Review, Vol.27 No.1, pp. 22-44.

Gibbs, G. R. (2007), “Thematic coding and categorizing”, in Gibbs, G. R. (Ed.), Analyzing qualitative data, Sage Publication, London, pp. 38-56.

Gillham, B. (2005), Research Interviewing: The range of techniques: A practical guide, McGrawHill Education, New York. 
Hinna, A., Scarozza, D. and Rotundi, F. (2018), "Implementing Risk Management in the Italian Public Sector: Hybridization between Old and New Practices", International Journal of Public Administration, Vol. 41 No. 2, pp. 110-128.

Hughes, O. (2010), “Does governance exist?”, in Osborne, S. P. (Ed.), The new public governance?: Emerging perspectives on the theory and practice of public governance”. Routledge, New York, pp. 103-120.

Janesick, V. J. (1994), “The dance of qualitative research design: Metaphor, methodolatry, and meaning", in Denzin, N. K. and Lincoln, Y. S. (Eds.), Handbook of qualitative research, Sage Publications, Thousand Oaks, CA, pp. 209-219.

Joseph, G. (2012), "Ambiguous but tethered: an accounting basis for sustainability reporting", Critical Perspectives on Accounting, Vol. 23 No. 2, pp. 93-106.

Klijn, E. H. (2012), New public management and governance: A comparison, Oxford handbook of governance, pp. 201-214.

Kumar, N., Stern, L. W. and Anderson, J. C. (1993). "Conducting interorganizational research using key informants", Academy of management journal, Vol. 36 No. 6, pp. 1633-1651.

Lane, D. C., Bianchi, C. and Bivona, E. (2010), "Public sector applications of the system dynamics approach", Systems Research and Behavioral Science, Vol. 27 No. 4, pp. 355-360.

Laurenza, E., Quintano, M., Schiavone, F. and Vrontis, D. (2018), “The effect of digital technologies adoption in healthcare industry: a case based analysis", Business Process Management Journal, Vol. 24 No. 5, pp. 1124-1144.

Leardini, C., Moggi, S. and Rossi, G. (2019), “The New Era of Stakeholder Engagement: Gaining, Maintaining, and Repairing Legitimacy in Nonprofit Organizations", International Journal of Public Administration, Vol. 42 No.6, pp. 520-532.

Leat, D. and Setzler, K. (2002), Towards holistic governance: the new reform agenda, Palgrave, Basingstoke, UK.

Locke, R., Leach, C., Kitsell, F. and Griffith, J. (2011), "The impact on the workload of the ward manager with the introduction of administrative assistants", Journal of Nursing Management, Vol. 19 No. 2, pp. 177-185. 
Maani, K. E. and R. Y. Cavana. (2007), Systems Thinking, System Dynamics: Understanding Change and Complexity, Printice Hall, Aukland.

Nikolaou, I., Evangelinos, K., and Leal Filho, W. (2015), “A system dynamic approach for exploring the effects of climate change risks on firms' economic performance", Journal of cleaner production, Vol. 103, pp. 499-506.

Osborne, S. P. (2010), "The new public governance: Emerging perspectives on the theory and practice of public governance". Routledge, New York, USA.

Pádua, S. I. D. and Jabbour, C. J. C. (2015), "Promotion and evolution of sustainability performance measurement systems from a perspective of business process management: from a literature review to a pentagonal proposal”, Business Process Management Journal, Vol. 21 No. 2, pp. 403-418.

Papachristos, G. and Adamides, E. (2016), “A retroductive systems-based methodology for sociotechnical transitions research", Technological Forecasting and Social Change, Vol.108, pp. 1-14.

Parker, L. D. (2012), “Qualitative management accounting research: Assessing deliverables and relevance", Critical perspectives on accounting, Vol. 23 No. 1, pp. 54-70.

Patton, M. Q. (2002), Qualitative research and evaluation methods. Sage Pubblication, Thousand Oakes, CA.

Porter N.W. (2018), “The Value of System Dynamics Modeling in Policy Analytics and Planning”, in Gil-Garcia J., Pardo T., Luna-Reyes L. (eds), Policy Analytics, Modeling, and Informatics. Public Administration and Information Technology, Vol. 25, Springer, Cham, pp. 123-150.

Qudrat-Ullah, H. (2012), "On the validation of system dynamics type simulation models", Telecommunication Systems, Vol. 51 No. 2-3, pp. 159-166.

Rhineberger, G. M., Hartmann, D. J. and Van Valey, T. L. (2005), “Triangulated Research Designs — A Justification?", Journal of Applied Sociology, Vol. 22 No. 1, pp. 56-66.

Richardson, G. P. (2011), "Reflections on the foundations of system dynamics", System Dynamics Review, Vol. 27 No. 3, pp. 219-243.

Richardson, G.P. and D. F. Andersen, (2010), “Systems Thinking, Mapping, and Modeling for Group Decision and Negotiation", in Eden, C. and Kilgour, D.N. (Eds), Handbook for Group Decision and Negotiation, Springer, Dordrecht, pp. 313-324. 
Rinaldi, M., Montanari, R. and Bottani, E. (2015), "Improving the efficiency of public administrations through business process reengineering and simulation: A case study", Business Process Management Journal, Vol. 21 No. 2, pp. 419-462.

Roulston, K. (2010), Reflective interviewing: A guide to theory and practice, Sage, London, UK.

Rundh, B. (2009), "Packaging design: creating competitive advantage with product packaging", British Food Journal, Vol. 111 No. 9, pp. 988-1002.

Scuotto, V., Ferraris, A. and Bresciani, S. (2016), "Internet of Things: Applications and challenges in smart cities: a case study of IBM smart city projects”, Business Process Management Journal, Vol. 22 No. 2, pp. 357-367.

Senneset, G., Midtstraum, R., Forås, E., Vevle, G. and Mykland, I. H. (2010), “Information models leveraging identification of returnable transport items", British Food Journal, Vol. 112 No. 6, pp. 592-607.

Siggelkow, N. (2007), "Persuasion with case studies", Academy of management journal, Vol. 50 No, 1, pp. 20-24.

Silverman, D. (2013), Doing qualitative research: A practical handbook, Sage Publications, London.

Sorci, P. (2019), “Governing Local Area Development through Dynamic Performance Management. Towards an Inter-Institutional Outcome-Based Perspective", Public Organization Review, Vol. 19 No.2, pp. 159-177.

Stake, R. E. (1995), The Art of Case Study Research, Sage, Thousand Oaks, CA.

Sterman, J. (1994), “Learning in and about complex systems”, System Dynamics Review, Vol. 10 No. 2-3, pp. 291-330.

Stoker, G. (2006), “Public value management: a new narrative for networked governance?”, The American review of public administration, Vol. 36 No. 1, pp. 41-57.

Strauss, A. and Corbin, J. (1990), Basics of qualitative research, Sage publications, Newbury Park, CA. 
Svara, J.H. (2001), "The myth of the dichotomy: Complementarity of politics and administration in the past and future of public administration", Public administration review, Vol. 61 No. 2, pp. 176183.

Tan, Y., Jiao, L., Shuai, C. and Shen, L. (2018), “A system dynamics model for simulating urban sustainability performance: A China case study”, Journal of cleaner production, Vol. 199, pp. 11071115.

Thompson, F. and Rizova, P. (2015), "Understanding and creating public value: Business is the engine, government the flywheel (and also the regulator)", Public Management Review, Vol. 17 No. 4, pp. 565-586.

Trivelli, L., Apicella, A., Chiarello, F., Rana, R., Fantoni, G. and Tarabella, A. (2019), "From precision agriculture to Industry 4.0: Unveiling technological connections in the agrifood sector", British Food Journal, Vol. 121 No. 8, pp. 1730-1743.

Trkman, P., Mertens, W., Viaene, S. and Gemmel, P. (2015), "From business process management to customer process management", Business process management journal, Vol. 21 No. 2, pp. 250266.

Weske, M. (2019), “Business Process Modeling Foundation”, in Weske, M. (Ed.), Business Process Management, Springer, Berlin, Heidelberg, pp. 71-122.

Wheat, I.D. and Bardach, E. (2018), "Disappointing Outcomes: Can Implementation Modeling Help?", in Borgonovi E., Anessi-Pessina E. and Bianchi C. (Eds), Outcome-Based Performance Management in the Public Sector. System Dynamics for Performance Management Vol. 2, Springer, Cham, pp. 179-200.

Wolff, S. (2004), “Analysis of documents and records”, in U. Flick, U., Von Kardoff E. and Steinke, I. (Eds.), A companion to qualitative research, Sage, London, pp. 284-289.

Wollmann, H., \& Marcou, G. (2010), The provision of public services in Europe: Between state, local government and market, Edward Elgar Publishing.

Wolstenholme, E. (2004), "Using generic system archetypes to support thinking and modeling", System Dynamics Review, Vol. 20 No.4, pp. 341-356.

$\mathrm{Xu}$, R., Sun, Q. and Si, W. (2015), "The third wave of public administration: The new public governance", Canadian Social Science, Vol. 11, No. 7, pp. 11-21. 
Yin, R. K. (2017), Case study research and applications: Design and methods, Sage Publications, Thousand Oaks, CA. 
Figure 1. Structure of the research framework

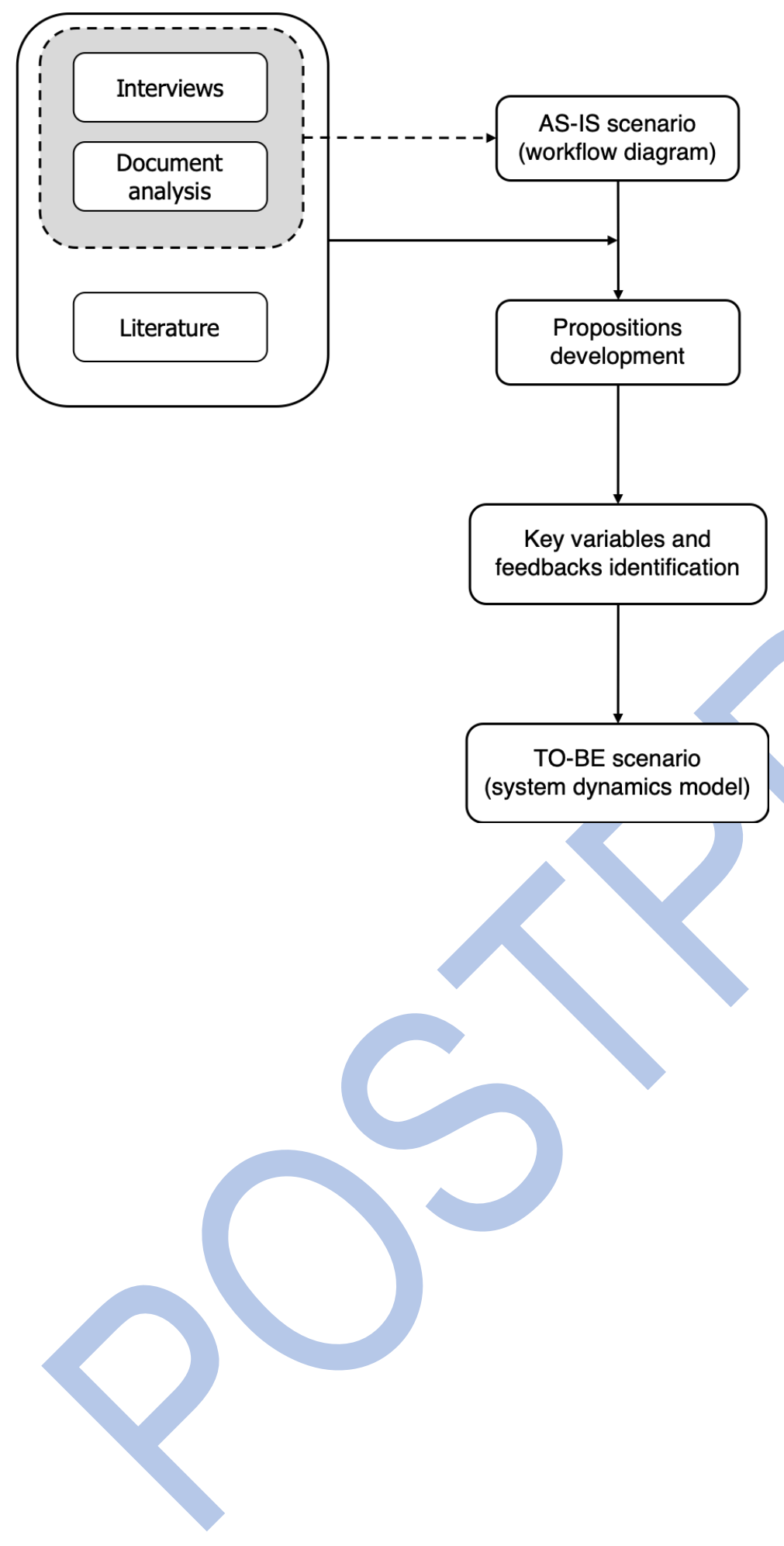


Figure 2. The tax collection workflow

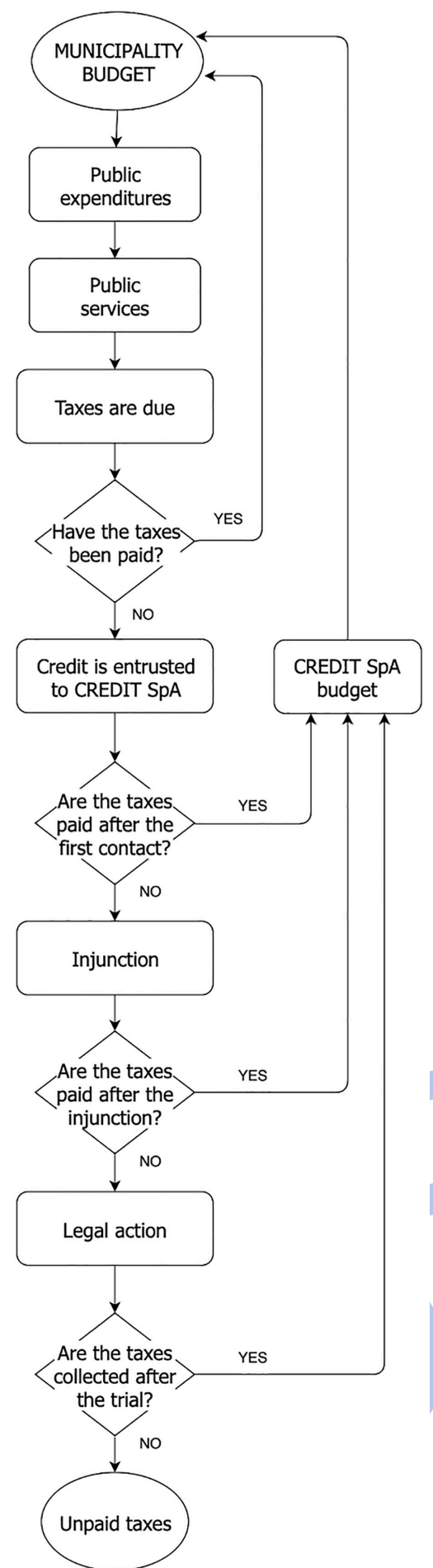

Source(s): Authors own elaboration 
Figure 3. The assessment, collection, and liquidation activity of CREDIT SpA

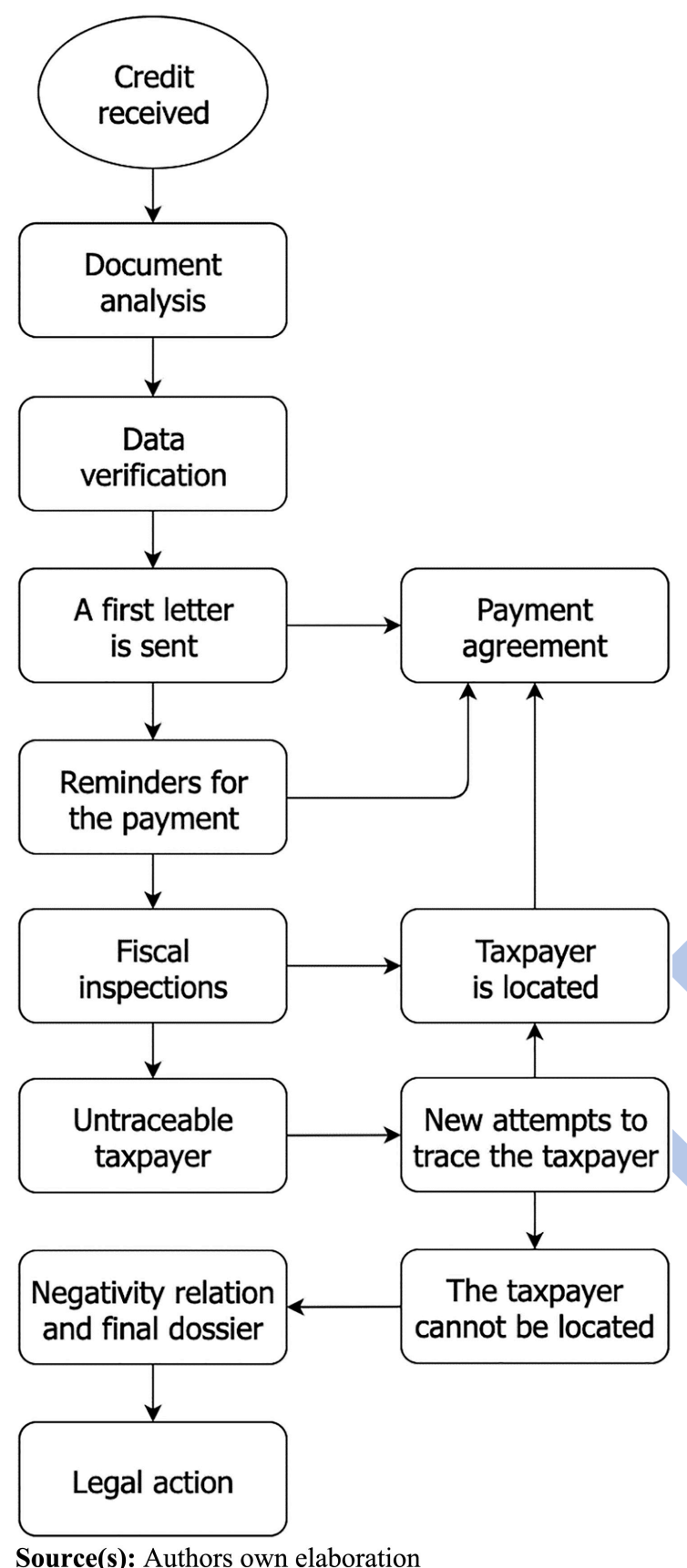


Figure 4. The ideal workflow of citizens at CREDIT SpA's offices

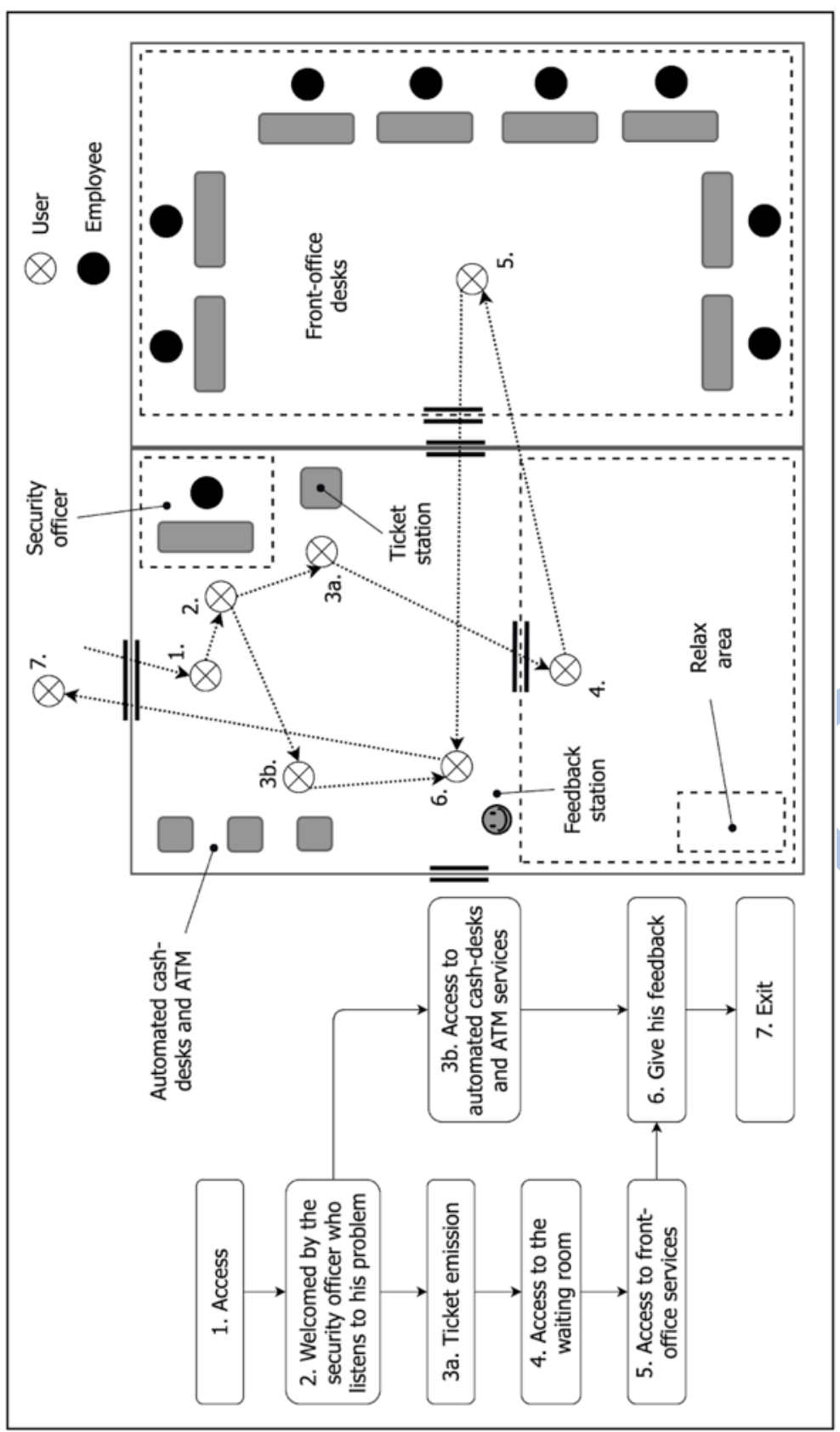


Figure 5. The causal loop diagram of the tax collection activity

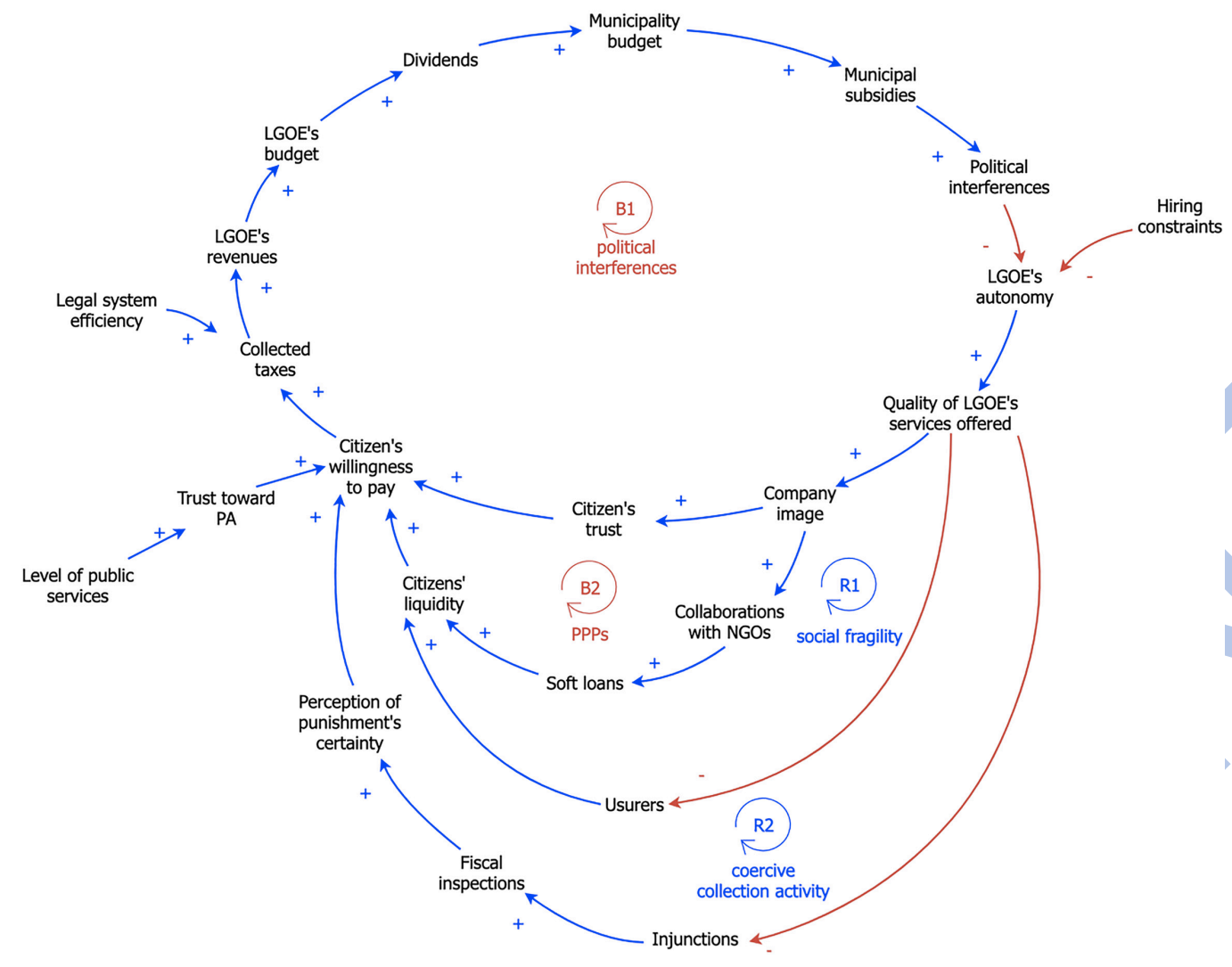

Source(s): Authors own elaboration 


$$
p^{p^{p^{2}}}
$$


Figure 7. Two loops affected by external actors. Collaborating with NGOs leads to a self-balancing loop. The presence of usurers leads to a loop that reinforces social fragility

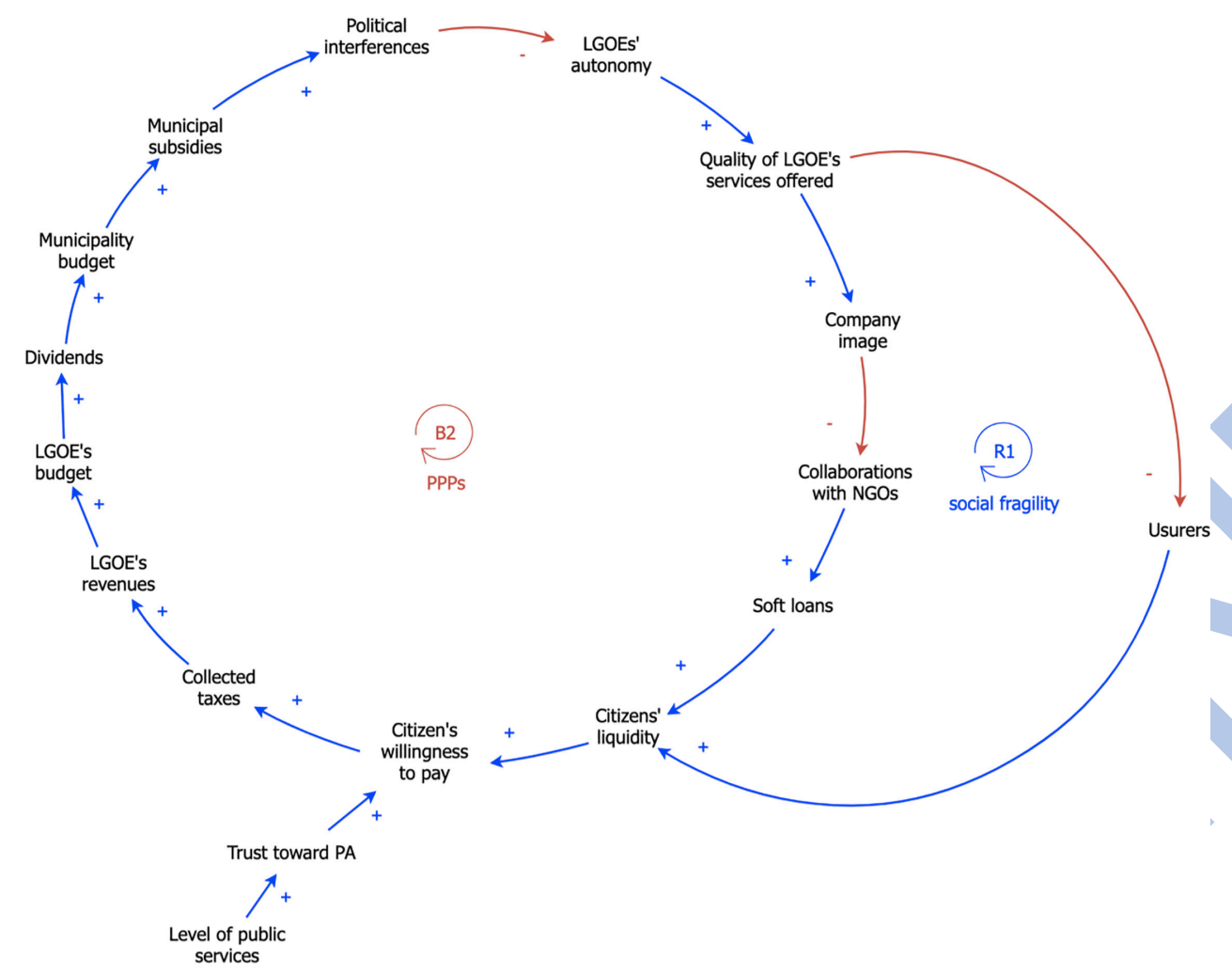

Source(s): Authors own elaboration 
Figure 8. The self-reinforcing loop linked to the coercive collection activity

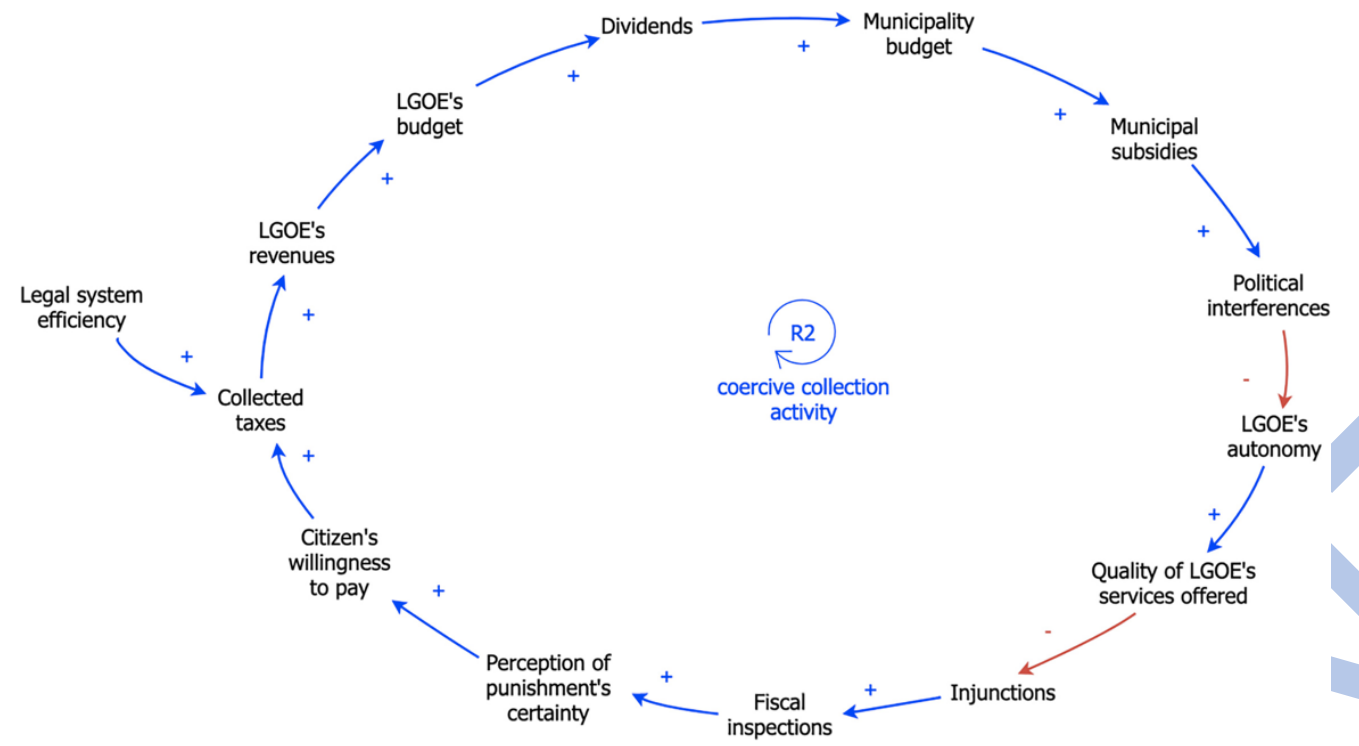

Source(s): Authors own elaboration 
Table 1. Interviews list

\begin{tabular}{llccc}
\hline & Function & Code & Date & Duration \\
\hline CREDIT SpA & General Director/CEO & C1 & $01 / 17 / 2018$ & 47 Min \\
& Chief Risk Officer (CRO) & C2 & $03 / 06 / 2018$ & 54 Min \\
& Controller & C3 & $03 / 15 / 2018$ & $48 \mathrm{Min}$ \\
& Legal affairs and contracts manager & C4 & $03 / 21 / 2018$ & $46 \mathrm{Min}$ \\
& Front desk Employee (consultant) & C5 & $05 / 09 / 2018$ & 51 Min \\
& Front desk employee (consultant) & C6 & $11 / 06 / 2018$ & $50 \mathrm{Min}$ \\
& Front desk employee (cashier) & C7 & $11 / 20 / 2018$ & 57 Min \\
& Front desk employee (cashier) & C8 & $02 / 13 / 2019$ & 59 Min \\
Municipality & Director of the Municipality participation area & M1 & $04 / 18 / 2018$ & 49 Min \\
& Executive of the Municipality participation area & M2 & $01 / 16 / 2019$ & 47 Min \\
& Municipal employee of the Municipality participation & M3 & $02 / 07 / 2019$ & 51 Min \\
& area & & & \\
Municipal employee of the Municipality participation & M4 & $03 / 19 / 2019$ & 45 Min \\
& area & & \\
\hline
\end{tabular}

